\title{
Treatment of cardiovascular risk factors to prevent cognitive decline and dementia: a systematic review
}

This article was published in the following Dove Press journal:

Vascular Health and Risk Management

16 August 2010

Number of times this article has been viewed

\author{
Suzanne A Ligthart ${ }^{\prime}$ \\ Eric P Moll van Charante' \\ Willem A Van Gool ${ }^{2}$ \\ Edo Richard ${ }^{2}$ \\ 'Department of General Practice, \\ ${ }^{2}$ Department of Neurology, \\ Academic Medical Center, University \\ of Amsterdam, Amsterdam, The \\ Netherlands
}

Background: Over the last decade, evidence has accumulated that vascular risk factors increase the risk of Alzheimer disease (AD). So far, few randomized controlled trials have focused on lowering the vascular risk profile to prevent or postpone cognitive decline or dementia.

Objective: To systematically perform a review of randomized controlled trials (RCTs) evaluating drug treatment effects for cardiovascular risk factors on the incidence of dementia or cognitive decline.

Selection criteria: RCTs studying the effect of treating hypertension, dyslipidemia, hyperhomocysteinemia, obesity, or diabetes mellitus (DM) on cognitive decline or dementia, with a minimum follow-up of 1 year in elderly populations.

Outcome measure: Cognitive decline or incident dementia.

Main results: In the identified studies, dementia was never the primary outcome. Statins ( 2 studies) and intensified control of type II DM (1 study) appear to have no effect on prevention of cognitive decline. Studies on treatment of obesity are lacking, and the results of lowering homocysteine ( 6 studies) are inconclusive. There is some evidence of a preventive effect of antihypertensive medication (6 studies), but results are inconsistent.

Conclusion: The evidence of a preventive treatment effect aimed at vascular risk factors on cognitive decline and dementia in later life is scarce and mostly based on secondary outcome parameters. Several important sources of bias such as differential dropout may importantly affect interpretation of trial results.

Keywords: cardiovascular risk factors, cognitive decline, dementia, prevention

Apart from a dramatic impact on the personal life of patients and their caregivers, dementia places a high burden on social and economic resources. With an ageing population, the prevalence of dementia will continue to rise in the coming decades. Since effective treatments are lacking, prevention of dementia deserves high priority. Alzheimer disease (AD) and vascular dementia (VaD) are the most prevalent forms of dementia, together accounting for up to $80 \%$ of all cases of dementia. ${ }^{1}$

The strict division between $\mathrm{AD}$ and $\mathrm{VaD}$ has faded with advancing research in neuropathology, neuroradiology, and epidemiology. In recent years, the vascular component of AD has become increasingly recognized. ${ }^{2}$ Several cohort studies have shown that in most dementia patients, irrespective of their clinical diagnosis, mixed pathology is found at autopsy, including mostly Alzheimer changes (amyloid- $\beta$ plaques and intracellular tangles) and cerebrovascular lesions (both infarcts and white matter lesions (WML)). ${ }^{3-5}$ Imaging studies have shown that WML and silent cerebral infarcts increase the risk of future dementia and that cerebrovascular lesions are common in $\mathrm{AD}$, where they contribute to dementia severity. ${ }^{6,7}$ 
Presently, compelling evidence from numerous prospective cohort studies of the relationship between vascular risk factors and cognitive deficits has been found. Hypertension, dyslipidemia, hyperhomocysteinemia, obesity, and diabetes mellitus (DM) at midlife have all been associated with an increased risk of cognitive decline and dementia in later life. ${ }^{8-12}$ In several observational studies, the use of antihypertensive drugs and statins, as well as the intake of folate, vitamin B6, and vitamin B12 have been associated with a decreased risk of dementia. ${ }^{13-16}$

Results from a recent randomized controlled trial (RCT) show that an intervention aimed at improving cardiovascular risk profile can slow down the progression of WML in early $\mathrm{AD}$, but has no effect on cognition, behavior, or activities of daily living. ${ }^{17}$ Whether treatment of vascular risk factors in cognitively intact elderly can postpone or prevent cognitive decline and dementia is subject to debate.

In this systematic review we give an overview of RCTs in which the effect of established medical treatments of vascular risk factors on cognitive decline and dementia is studied. Lifestyle alterations such as exercise programs and diet are not in the scope of this review. Potential sources of bias in this specific field are discussed, as well as future research.

\section{Objective}

To systematically review all RCTs in which the effect of medical treatment aimed at vascular risk factors, ie, hypertension, dyslipidemia, hyperhomocysteinemia, obesity, and DM type II on the incidence of dementia or cognitive decline, were investigated.

\section{Methods}

\section{Literature review}

A systematic literature review was carried out to identify all available RCTs in which the effect of treatment of established vascular risk factors on the incidence of all cause dementia or cognitive decline was studied. We searched for RCTs from 1990 onwards because the relationship between vascular risk factors and all forms of dementia was not widely recognized before this time. The search was restricted to articles in English and we were assisted by a clinical librarian with experience in performing systematic reviews. Only RCTs were included in this review, to minimize the influence of all forms of bias, and particularly selection bias. To be able to find any effect on dementia or long-term cognitive decline, studies targeting elderly people (mean age at baseline at least 60 years) and with a follow-up of at least 1 year, were considered eligible.

All studies in which results on cognitive decline or dementia were reported were included in this review, leaving precise definition of cognitive decline to the discretion of the original investigators. The sensitivity and clinical relevance of different testing methods are subject to debate and are addressed later in this review.

The following (Mesh) search terms were used: ("randomized controlled trial" or "controlled clinical trial" or "randomized" or "randomly" or "trial") in combination with ("dementia" or "mild cognitive impairment" or "Alzheimer" or "cognitive decline") and ("older" or "elder*" or "aged" or "later life") and the following search terms: a) "hypertension" or "antihypertens*" or "blood pressure" b) "cholesterol" or "dyslipidemia" or "hypercholesterolemia" or "lipid lowering" c) "homocysteine" d) "diabetes mellitus" or "glucose control" or "diabetes" or "diabetic" or "hypoglycemic" and e) "adiposity" or "obesit*".

MEDLINE (PubMed) was searched on November 30, 2009. First, articles were scanned on titles and abstracts independently by two reviewers (SL, ER). Articles were retained if they met the following inclusion criteria: 1) original randomized controlled intervention trial; 2) drug treatment intervention targeted at lowering blood pressure, improving lipid profile, lowering homocysteine, optimizing treatment of diabetes mellitus type II, or treating overweight; and 3) assessing cognitive decline or incident all-cause dementia as primary or secondary outcome parameters in a population with a mean age of at least 60 years and a follow-up time of at least 1 year. EMBASE and the Cochrane Central register of Controlled trials (clinical trials) were searched with the same keywords. In addition, the Cochrane Database of Systematic Reviews was explored using the search terms (dementia or "mild cognitive impairment" or Alzheimer or "cognitive decline") to identify existing systematic reviews on this topic. Finally, reference lists of all articles identified were searched.

\section{Data collection}

Articles that met inclusion criteria were analyzed by two reviewers (SL, ER). Data on type and number of participants, intervention, (the effect on) primary outcomes, outcome measures on cognitive decline or dementia, duration of follow-up, completeness of follow-up, and conclusions drawn by authors were collected. The main limitations of each study were identified as well as main strengths. 


\section{Results}

The MEDLINE search yielded 1292 articles, of which 87 were selected by screening titles and abstracts. The EMBASE search (1362 articles) yielded one additional study that was not found in the initial search in PubMed. In the Cochrane search ( 880 articles) no additional RCTs were found. Finally, 16 original studies (43 papers) were included in this review; six on hypertension, two on dyslipidemia, none on obesity, one on diabetes mellitus type II, six on lowering homocysteine, and one study with a multifactorial intervention. Three additional studies on cardiovascular and diabetes management are ongoing and will be described in this review, as well as the main characteristics of excluded studies. The Cochrane search for systematic reviews revealed six systematic reviews for separate risk factors: one on hypertension, one on statins, one on diabetes mellitus, and three on B vitamins. These will be discussed below.

\section{Excluded studies}

After selection based on titles and abstracts, studies were excluded subsequently for the following reasons: mean follow up shorter than 1 year $(n=35)$, mean age of participants $<60$ years $(n=3)$, cognitive decline or dementia was no primary or secondary outcome $(\mathrm{n}=2)$, and participants already suffering from $\operatorname{AD}(n=4)$. Many studies on antihypertensive treatment conducted between 1990 and 1995 compared the effect of two antihypertensive agents (eg, a beta-blocker and an ACE-inhibitor) on cognitive function to rule out a negative short term effect of medication on cognition (for examples see Fogari et al ${ }^{18}$ or Goldstein et al). ${ }^{19}$ The follow-up time was short (from several weeks to a maximum of 6 months), rendering these studies prone to a type II error for the evaluation of long-term effects on cognition. In general, no adverse effects of antihypertensive treatment on short-term cognition were reported.

Four studies on diabetes management were excluded due to their having relatively young populations (mean age 52 years) with a short follow up (6-24 weeks), reporting no or only small positive effects of glycemic control on some domains of short-term cognitive function or quality of life. ${ }^{20-23}$ Excluded studies in which treatment was aimed at lowering homocysteine levels were often restricted to 6 months. ${ }^{24,25}$

\section{Hypertension}

Six studies evaluating the relationship between antihypertensive treatment and cognitive decline/dementia were identified (see Table 1 for details).
The number of participants in studies ranged from 2418 to 6105 . In all studies, cognitive decline and dementia were measured as secondary outcome parameters. Age at inclusion varied from $\geq 60 / 65$ years (SHEP, ${ }^{26,27}$ MRC, ${ }^{28}$ Syst-Eur, ${ }^{29,30}$ PROGRESS ${ }^{31}$ ), to $\geq 70$ years $\left(\mathrm{SCOPE}^{32,33}\right.$ ), and even to $\geq 80$ years (HYVET). ${ }^{34}$ Generally, participants with a systolic blood pressure of $\geq 160 \mathrm{mmHg}$ (both treated and untreated in SHEP/SCOPE/HYVET) and without prior stroke were eligible, except for PROGRESS in which only participants with a stroke or transient ischemic attack (TIA) in the previous 5 years were included, regardless of blood pressure. An upper limit of $179 \mathrm{mmHg}$ for systolic blood pressure was an inclusion criterion in the SCOPE trial, in contrast to the other studies.

All included studies on hypertension are placebocontrolled trials. In five trials a diuretic was part of the study medication, in combination with a beta-blocker $(n=2)$ or ACE-inhibitor $(\mathrm{n}=3)$. In SCOPE an angiotensin II type 1 (AT1) receptor blocker was the studied drug, whereas SystEur was the only trial in which a calcium channel blocker was studied (combined with an ACE-inhibitor and/or diuretic if necessary).

Many patients received additional (open label) antihypertensive medication in both groups to achieve acceptable blood pressure values. For example, in Syst-Eur, half of the patients in the placebo group remained on their original study medication and in the MRC trial this was only $38 \%$. In SCOPE, $84 \%$ of participants in the placebo group received antihypertensive medication.

To assess cognitive function, the Mini-Mental State Examination (MMSE), a widely used screening instrument for cognitive impairment, was used in most studies (Syst-Eur, SCOPE, PROGRESS, and HYVET). In the SHEP study, cognitive screening was performed by the short-comprehensive assessment and referral evaluation (short-CARE) questionnaire. The PALT (paired associate learning test) and the TMT (trail making test) were used in the MRC trial to measure cognition. In one center of the SCOPE trial $(n=257)$, an additional extensive assessment battery was used to assess cognition. ${ }^{33}$

Follow-up of the included trials ranged from 2.2 years (HYVET) to 5 years (SHEP). In a study by Di Bari et al the risk of "differential dropout" is highlighted with regard to the SHEP trial. ${ }^{27}$ This selective dropout of patients is especially plausible in the case of cognitive decline or dementia, in which progression of symptoms could lead to unwillingness to participate further in the study. In addition, loss to 
Table I Hypertension

\begin{tabular}{|c|c|c|c|c|c|}
\hline $\begin{array}{l}\text { Authors (study } \\
\text { name), year of } \\
\text { publication }\end{array}$ & $\begin{array}{l}\text { Population } \\
\text { characteristics }\end{array}$ & $\begin{array}{l}\text { Intervention } \\
\text { (number of } \\
\text { participants) }\end{array}$ & $\begin{array}{l}\text { Primary end } \\
\text { points (\% RRR } \\
\text { for stroke) }\end{array}$ & $\begin{array}{l}\text { Mean } \\
\text { follow-up }\end{array}$ & $\begin{array}{l}\text { Effect on cognitive } \\
\text { function (test) }\end{array}$ \\
\hline $\begin{array}{l}\text { SHEP, SHEP } \\
\text { study group, }{ }^{26,27} \\
\text { I99| }\end{array}$ & $\begin{array}{l}\text { isolated systolic HTN } \\
(160-219 \mathrm{mmHg}), \\
\text { age } \geq 60 \mathrm{y}\end{array}$ & $\begin{array}{l}\text { chlorthalidone } \pm \text { atenolol } \\
\text { or reserpine versus } \\
\text { placebo }(n=2365 / 237 \text { I) }\end{array}$ & $\begin{array}{l}\text { fatal/nonfatal stroke } \\
(36 \%)\end{array}$ & $5.0 y$ & $\begin{array}{l}\text { no significant difference in } \\
\text { incidence of } C D \\
\text { (shortCARE) }\end{array}$ \\
\hline $\begin{array}{l}\text { MRC trial, } \\
\text { Prince et } \mathrm{al}^{28} \\
1996\end{array}$ & $\begin{array}{l}\text { not on anti- } \\
\text { hypertensive } \\
\text { medication, age } \\
65-74 \text { y }\end{array}$ & $\begin{array}{l}\text { hydrochlorothiazide/ } \\
\text { amiloride or atenolol } \\
\text { versus placebo } \\
(n=633 / 640 / 13 \mid 1)\end{array}$ & $\begin{array}{l}\text { stroke/coronary } \\
\text { events/mortality } \\
(31 \%)\end{array}$ & $4.5 y$ & $\begin{array}{l}\text { no effect on cognitive } \\
\text { performance } \\
\text { (PALT, TMT A) }\end{array}$ \\
\hline $\begin{array}{l}\text { Syst-Eur, } \\
\text { Forette et al }{ }^{29,30} \\
\text { 1998, } 2002\end{array}$ & $\begin{array}{l}\text { systolic HTN (160- } \\
219 \mathrm{mmHg}) \\
\text { age } \geq 60 \mathrm{y}\end{array}$ & $\begin{array}{l}\text { nitrendipine } \pm \text { enalapril } \\
\pm \text { hydrochlorothiazide } \\
\text { versus placebo } \\
(n=1238 / 1180)\end{array}$ & stroke (42\%) & $3.9 \mathrm{y}$ & $\begin{array}{l}55 \% \text { decrease in incidence } \\
\text { of dementia (MMSE) }\end{array}$ \\
\hline $\begin{array}{l}\text { SCOPE, Lithell } \\
\text { et } \mathrm{al}^{32,33} \\
2003 / 2008\end{array}$ & $\begin{array}{l}\text { treated or untreated } \\
\text { systolic HTN (I60- } \\
\text { I } 79 \mathrm{mmHg}) \\
\text { age } 70-89 \text { y }\end{array}$ & $\begin{array}{l}\text { candesartan versus } \\
\text { placebo }(n=2477 / 2460)\end{array}$ & $\begin{array}{l}\text { stroke, MI, } \\
\text { cardiovascular } \\
\text { mortality }(24 \%)\end{array}$ & $3.7 \mathrm{y}$ & $\begin{array}{l}\text { no decrease in incidence of } \\
\text { dementia } \\
\text { slightly less cognitive decline } \\
\text { in those with MMSE } \\
24-28 \text { /stroke (MMSE) }\end{array}$ \\
\hline 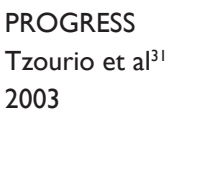 & $\begin{array}{l}\text { previous stroke or } \\
\text { TIA, mean age } 64 \text { y }\end{array}$ & $\begin{array}{l}\text { perindopril versus } \\
\text { placebo. Indapamide } \\
\text { added in both groups } \\
\text { when necessary } \\
(\mathrm{n}=305 \mathrm{I} / 3054)\end{array}$ & $\begin{array}{l}\text { recurrent stroke } \\
(28 \%)\end{array}$ & $3.9 y$ & $\begin{array}{l}\text { decrease in cognitive } \\
\text { decline ( } 3 \text { or more on } \\
\text { MMSE), non-significant } \\
\text { decrease in } \\
\text { dementia (MMSE) }\end{array}$ \\
\hline $\begin{array}{l}\text { HYVETCog, } \\
\text { Peters et } \mathrm{al}^{34} \\
2008\end{array}$ & $\begin{array}{l}\text { systolic HTN (I60- } \\
200 \mathrm{mmHg}) \\
\text { age } \geq 80 \mathrm{y}\end{array}$ & $\begin{array}{l}\text { indapamide } \pm \\
\text { perindopril versus } \\
\text { placebo }(n=1687 / 1649)\end{array}$ & stroke $(30 \%)$ & $2.2 \mathrm{y}$ & $\begin{array}{l}\text { no decrease in incidence of } \\
\text { dementia (MMSE) }\end{array}$ \\
\hline
\end{tabular}

Abbreviations: RRR, relative risk reduction; y, years; HTN, hypertension; CD, cognitive decline; PALT, paired-associate learning test; TMT, trail making test; MMSE, Mini-Mental State Examination; MI, myocardial infarction; TIA, transient ischemic attack.

follow-up is likely to occur more frequently when cognitive decline or dementia is present, because of high rates of institutionalization among these patients in comparison to healthy elderly participants. Under the assumption that hypertension is a risk factor for dementia, participants in the placebo group or participants with a high risk of cardiovascular events or a history of cardiovascular disease would be more likely to develop cognitive decline or dementia and as a consequence would also be more likely to end study participation. In the SHEP study, occurrence of cardiovascular events and assignment to placebo were both independently predictive for missed assessments. ${ }^{27}$ This potential selective dropout of patients is probably not specific to the SHEP study. In the MRC trial the dropout rate was high (the exact number of patients still included at follow-up was not reported) and participants that were lost to follow-up had lower cognitive scores at baseline. In the Syst-Eur substudy on cognition, $76 \%$ of participants were willing to participate and, of these, $22 \%$ were not evaluated because of early trial termination of their participation (less than 1 year).

The primary outcome parameters in all studies were stroke only or stroke in combination with coronary events/myocardial infarction and (cardiovascular) death. In all studies, the incidence of fatal and nonfatal stroke was significantly reduced. The relative risk reduction for stroke varied from 24\% (SCOPE) to 42\% (Syst-Eur). HYVET was the first RCT to report the effects of antihypertensive treatment in participants aged 80 years and older and showed a significant decrease of stroke after an average follow-up of 2.2 years, which led to early termination of this study. Participants were mostly recruited in Eastern Europe and China (95\%) where the risk of stroke is higher than in Western Europe. ${ }^{35}$ In 5 of 6 studies, no significant effect on the incidence of dementia was found. The Syst-Eur trial, of which the first results were published in 1998, was the only RCT that showed a convincing decrease on incidence of dementia by $50 \%$ after two years and $55 \%$ after a mean of 3.9 years of follow-up.

In the SCOPE trial no differences in incident dementia or MMSE score were found. In a subgroup analysis that was performed later and published in 2008, a significant positive effect on some cognitive domains (attention and episodic memory) was reported through more sensitive testing methods than the MMSE. The clinical relevance of these results is 
questioned by the authors. In the PROGRESS trial, cognitive decline (defined by a decrease in MMSE score of 3 or more points) was significantly lower in the treatment group $(9.1 \%$ versus $11.0 \%, P=0.01$ ) next to a nonsignificant decrease of incident dementia $(6.3 \%$ versus $7.1 \%, P=0.2)$.

The results of the most recent HYVET-Cog study on indapamide with or without perindopril show a nonsignificant effect of antihypertensive treatment with a hazard ratio for incident dementia of 0.86 (95\% CI 0.67-1.09). When these results were combined with the results of SHEP, Syst-Eur, and PROGRESS in a meta-analysis, the hazard ratio was 0.87 (95\% CI 0.76-1.00). ${ }^{34}$

One Cochrane systematic review is available (2009), only for patients without prior cerebrovascular disease, in which also the (single blind) MRC trial was excluded. ${ }^{36}$ The authors conclude that the available evidence for prevention of cognitive impairment or dementia by blood pressure lowering in late life is not conclusive. Two potential sources of substantial bias were recognized: the large number of patients lost to follow-up and active treatment of blood pressure in placebo groups that may have led to underestimation of a treatment effect.

\section{Dyslipidemia}

Two randomized clinical trials that met our inclusion criteria evaluated the effect of statin use on cognition (Table 2). The Heart Protection Study (HPS) compared the use of simvastatin $40 \mathrm{mg}$ to placebo in 20,536 participants aged 40-80 (5806>70 y), ${ }^{37}$ and the PROSPER study compared pravastatin $40 \mathrm{mg}$ to placebo in 5804 participants aged 70-82 (mean 75.3). ${ }^{38,39}$ Dyslipidemia was not required for inclusion in either trial. Lipid levels at baseline were largely comparable between the two studies, with total cholesterol (in mmol/L) of 5.9 (HPS) and 5.7 (PROSPER), LDL 3.4 (HPS) and 3.8 (PROSPER), and triglycerides 2.1 (HPS) and 1.5 (PROSPER). Levels of LDL were successfully reduced in HPS and PROSPER ( -1.4 and -1.3 respectively).
Participants were included in HPS if they were considered to be at a substantial 5 year risk of death from coronary heart disease based on medical history (coronary disease, noncoronary occlusive disease, diabetes, or hypertension). Participants were included in PROSPER if they had preexisting vascular disease (coronary, cerebral, or peripheral) or were considered to be at increased risk for this, because of smoking, diabetes, or hypertension. Non-study statin treatment occurred in the placebo group in 10\% in PROSPER and this was on average $17 \%$ in HPS (ranging from $4 \%$ in the first year to $32 \%$ at the end of the fifth year). HPS had an average follow-up of 5 years and PROSPER of 3.5 years. The primary outcome parameters in HPS were mortality and fatal and nonfatal vascular events, and in PROSPER the primary outcome parameter was a composite endpoint of coronary death, nonfatal myocardial infarction, and fatal or nonfatal stroke. Both trials used cognitive function as a secondary outcome parameter. In the HPS no cognitive assessment was made at baseline, and at follow-up the Telephone Interview for Cognitive Status (TICS) was used. In the PROSPER, four cognitive outcome parameters were used: MMSE, two tests for executive function (Stroop color-word test and the letter digit coding test), and one memory test (15 Picture Learning test, PLT). No effect on any of the used cognitive outcome parameters was found in either HPS or PROSPER. The HPS study reported $23.7 \%$ (simvastatin) versus $24.2 \%$ (placebo) of the participants as having any cognitive impairment at follow-up. The PROSPER study reported a decline in all measured cognitive domains which was comparable in the two groups, as expected with advancing age in this group. Although the methods used to assess cognitive decline in both studies, especially the HPS-study, are limited, it seems unlikely that different ways of assessing cognitive decline would have yielded different results.

Since the publication of a Cochrane review on this subject, ${ }^{40}$ no new trials have been published, except for a more detailed description of the cognitive outcomes of the

Table 2 Dyslipidemia

\begin{tabular}{|c|c|c|c|c|c|}
\hline $\begin{array}{l}\text { Authors, year } \\
\text { of publication }\end{array}$ & $\begin{array}{l}\text { Population } \\
\text { characteristics }\end{array}$ & $\begin{array}{l}\text { Intervention (number } \\
\text { of participants) }\end{array}$ & $\begin{array}{l}\text { Primary end-points } \\
\text { (outcome) }\end{array}$ & Follow-up & $\begin{array}{l}\text { Effect on cognitive } \\
\text { function (test) }\end{array}$ \\
\hline 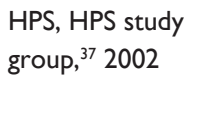 & $\begin{array}{l}\text { occlusive arterial } \\
\text { disease or DM, age } \\
40-80 \text { y }\end{array}$ & $\begin{array}{l}\text { simvastatin versus } \\
\text { placebo } \\
(n=10269 / 10267)\end{array}$ & $\begin{array}{l}\text { all cause mortality/ } \\
\text { coronary death } \\
(\mathrm{HR} 0.87, P=0.0003)\end{array}$ & $5 y$ & no effect on cognition (TICS) \\
\hline $\begin{array}{l}\text { PROSPER, } \\
\text { Shepherd } \\
\text { et } \mathrm{al}^{38,39} 2002\end{array}$ & $\begin{array}{l}\text { history of VAD or } \\
\text { risk factors, age } \\
70-82 \text { y }\end{array}$ & $\begin{array}{l}\text { pravastatin versus } \\
\text { placebo }(n=2891 / 2913)\end{array}$ & $\begin{array}{l}\text { coronary death, } \\
\text { nonfatal } \mathrm{MI} \text {, stroke } \\
(\mathrm{HR} 0.85, P=0.014)\end{array}$ & $3.2 \mathrm{y}$ & $\begin{array}{l}\text { no effect on cognitive function } \\
\text { or disability (MMSE, NP test } \\
\text { battery) }\end{array}$ \\
\hline
\end{tabular}

Abbreviations: DM, diabetes mellitus; y, years; HR, hazard ratio; TICS, telephone interview for cognitive status; VAD, vascular disease; MMSE, mini mental state examination; NP, neuropsychological. 
PROSPER study. ${ }^{41}$ We can conclude that there is no evidence that the use of statins in elderly participants has a favorable effect on cognitive decline.

\section{Hyperhomocysteinemia}

Six studies on lowering homocysteine were identified. Overall, plasma homocysteine lowering was achieved by prescribing a combination of folic acid and other high dose B vitamins (vitamin B6, vitamin B12).

The total number of participants varied from 185 to 2009 per study. Patients were mostly selected on elevated serum total homocysteine levels ( $\geq 13$ or $\geq 15 \mathrm{mmol} / \mathrm{L}$ ), apart from the studies by Stott et $\mathrm{al}^{42}$ and Kang et $\mathrm{al}^{43}$ in which homocysteine levels were not specificed and only patients with high risk of cardiovascular disease (ischemic heart disease, TIA/stroke, peripheral arterial disease) were included. In the substudy by Viswanathan and colleagues, ${ }^{44} 150$ participants from each treatment arm of the original VISP study with the highest plasma homocysteine levels and who did not have a stroke during follow-up were post-hoc included for analysis of cognitive function. The study by Brady et $\mathrm{a}^{45}$ was aimed at a specific patient group with high levels of plasma homocysteine in combination with chronic or end-stage renal disease, of whom $36 \%$ was on hemodialysis. The studies by Brady et al and Viswanathan et al included very young patients ( $>21$ and $>35$ years respectively), but average age of inclusion was similar to the other studies with 67 years.

In most studies, a combination of folic acid, vitamin B6, and vitamin B12 was used to lower homocysteine levels, versus placebo or a low dose B vitamins (Viswanathan et al). In the study by Stott et al folic acid was compared with the addition of vitamin B6, vitamin B12, or riboflavin versus placebo in 7 different groups $\left(n=23\right.$ /group). Durga et $\mathrm{al}^{46}$ assessed oral folic acid without other B vitamins versus placebo in patients with high homocysteine and low vitamin B12 levels.

Incident dementia was never an outcome in the included studies. Cognitive decline was the primary outcome in the studies by Durga et $\mathrm{al}^{46}$ and McMahon et $\mathrm{al}^{47}$ in which more extensive tests than the MMSE or TICS (a telephone version of the MMSE) only were used. Several combinations of neuropsychological tests were used in the different studies to measure cognition (see Table 3 for details).

Dropout rates varied from $0 \%$ to $26 \%$ in these studies. In the substudy from Viswanathan, there was no loss to follow up, while the original study suffered from high dropout (17\%), suggesting selection bias. The substudy on cognition started when the original study was already ongoing. This was also the case for the studies by Kang et al and Brady et al in which the studies on cognition started 1.2 and 4 years after the start of the original study, respectively.

The studies by McMahon et al and Durga et al were designed specifically to measure cognitive function. In the other trials, primary outcome parameters were vascular events or mortality except for the study by Stott et al in which the primary outcome parameter was plasma homocysteine level. In this study, a large effect on plasma homocysteine in the group treated with folic acid and vitamin B12 was achieved. In the study by McMahon et al plasma homocysteine concentration was decreased significantly but with no difference between the two groups.

In 5 of 6 studies, no effect was found of the lowering of plasma homocysteine levels on cognitive function. McMahon et al even found that patients in the intervention group scored significantly lower on one of the many subscales (trail making test B), which led to a lower combined cognitive score in the vitamin group $(P=0.05)$ than the placebo group. ${ }^{48}$ This is considered a chance finding by the authors. Only Durga et al found improvement in 3 of 5 cognitive domains (memory, processing speed, and sensorimotor speed). The authors themselves suggest as possible explanations: the long follow up (3 years), low dropout (1\%), and sensitive measurement of cognitive screening next to adequate selection of high risk patients (both high plasma homocysteine and low vitamin B12 status).

Three Cochrane systematic reviews were identified in our search. One review on the short-term effect of vitamin B6 found no benefit on cognition. In one review on vitamin B12 it was concluded that there was insufficient evidence for an effect on cognition. The review on folic acid with or without vitamin B12 and including the trial by Durga et al yielded inconsistent results and it was concluded that further research is required. ${ }^{49}$

\section{Diabetes mellitus type II and obesity}

Completed studies on the effect of medical treatment on reducing overweight on cognitive decline or dementia were not found. The ADVANCE study by Patel et al was the only completed study on type II diabetes mellitus management that was identified. ${ }^{50}$ Participants were suffering from type II diabetes and had a history of macro- or microvascular disease or at least one other cardiovascular risk factor. In total, 5571 participants with a minimum age of 55 years and a mean age of 66 years were randomized to intensive glucose control and 5569 to standard glucose control. The intervention consisted of the prescription of gliclazide modified release $30-120 \mathrm{mg}$, 
Table 3 Hyperhomocysteinemia

\begin{tabular}{|c|c|c|c|c|c|}
\hline $\begin{array}{l}\text { Authors, year of } \\
\text { publication }\end{array}$ & $\begin{array}{l}\text { Population } \\
\text { characteristics }\end{array}$ & $\begin{array}{l}\text { Intervention } \\
\text { (number of } \\
\text { participants) }\end{array}$ & $\begin{array}{l}\text { Primary end- } \\
\text { points (outcome) }\end{array}$ & $\begin{array}{l}\text { Follow- } \\
\text { up }\end{array}$ & $\begin{array}{l}\text { Effect on cognitive } \\
\text { function (test) }\end{array}$ \\
\hline Stott et $\mathrm{al}^{42} 2005$ & $\begin{array}{l}\text { ischemic } \\
\text { vascular disease, } \\
\text { age } \geq 65 \text { y }\end{array}$ & $\begin{array}{l}\text { oral vit } B 6, B \mid 2, \\
\text { folic acid ( } 7 \\
\text { groups versus } \\
\text { placebo, } n=185 \text {, } \\
23 \text { /group) }\end{array}$ & $\begin{array}{l}\text { plasma } \\
\text { homocysteine } \\
\text { (tHcy: 33\% } \\
\text { decrease) }\end{array}$ & Iy & $\begin{array}{l}\text { no effect on cognitive function } \\
\text { (letter digit coding test, TICS) }\end{array}$ \\
\hline $\begin{array}{l}\text { McMahon et a }{ }^{47} \\
2006\end{array}$ & $\begin{array}{l}\text { raised tHcy, } \\
(\geq 13 \mathrm{mmol} / \mathrm{L}) \\
\text { age }>65 \mathrm{y}\end{array}$ & $\begin{array}{l}\text { oral vit } B 6, B \mid 2 \text {, } \\
\text { folic acid versus } \\
\text { placebo } \\
(n=138 / 138)\end{array}$ & $\begin{array}{l}\text { plasma } \\
\text { homocysteine, } \\
\text { cognition (no effect } \\
\text { on tHcy) }\end{array}$ & $2 y$ & $\begin{array}{l}\text { no effect on cognition (extensive test } \\
\text { battery: MMSE, RAVLT, WMS, CWF } \\
\text { TMT) }\end{array}$ \\
\hline $\begin{array}{l}\text { Durga et al }{ }^{46} 2007 \\
\text { (substudy FACIT) }\end{array}$ & $\begin{array}{l}\text { tHcy } \geq 13 \text { and } \\
<26 \mathrm{mmol} / \mathrm{L} \text {. Vit } \\
\mathrm{BI} 2<200 \mathrm{pmol} / \mathrm{L} \text {, } \\
\text { age } 50-70 \mathrm{y} \\
\text { (mean: } 60 \mathrm{y} \text { ) }\end{array}$ & $\begin{array}{l}\text { oral folic acid or } \\
\text { placebo } \\
(406 / 4 / 3)\end{array}$ & $\begin{array}{l}\text { cognitive function } \\
\text { (tHcy } 26 \% \\
\text { decrease) }\end{array}$ & $3 y$ & $\begin{array}{l}\text { improvements in } 3 / 5 \text { domains (memory, } \\
\text { processing and sensorimotor speed) } \\
\text { (word learning, concept shifting, stroop } \\
\text { test, verbal fluency and letter-digit } \\
\text { substitution test) }\end{array}$ \\
\hline Kang et $\mathrm{al}^{43} 2008$ & $\begin{array}{l}\text { women with } \\
\text { CVD or }>2 \\
\text { cardiovascular } \\
\text { risk factors, } \\
\text { age }>65 \text { y }\end{array}$ & $\begin{array}{l}\text { oral vit } \mathrm{B} 6, \mathrm{BI} 2 \text {, } \\
\text { folic acid versus } \\
\text { placebo } \\
(\mathrm{n}=1002 / 1007)\end{array}$ & $\begin{array}{l}\text { sec. prevention of } \\
\text { cardiovascular } \\
\text { disease (no effect) }\end{array}$ & $5.4 y$ & $\begin{array}{l}\text { no effect on cognition ( } 5 \text { telephone } \\
\text { tests: TICS, word learning, immediate } \\
\text { and delayed recall, naming animals) }\end{array}$ \\
\hline $\begin{array}{l}\text { Brady et al }{ }^{45} 2009 \\
\text { (substudy VA HOST) }\end{array}$ & $\begin{array}{l}\text { chronic kidney } \\
\text { disease/end- } \\
\text { stage renal } \\
\text { disease, tHcy } \geq \\
15 \mathrm{mmol} / \mathrm{L} \text {, age } \\
\geq 21 \text { y }(\text { mean } 67 \mathrm{y})\end{array}$ & $\begin{array}{l}\text { high dose } B \\
\text { vitamins versus } \\
\text { placebo } \\
(320 / 339)\end{array}$ & $\begin{array}{l}\text { mortality, vascular } \\
\text { outcomes (no effect, } \\
\text { tHcy decrease: } 26.7 \% \text { ) }\end{array}$ & Iy & $\begin{array}{l}\text { no effect on cognition } \\
\text { (TICS, neuropsychological test battery: } \\
\text { backward/forward digit span, animal } \\
\text { naming). }\end{array}$ \\
\hline $\begin{array}{l}\text { Viswanathan et al }{ }^{44} \\
2009 \text { (substudy VISP) }\end{array}$ & $\begin{array}{l}\text { ischemic stroke, } \\
\text { tHcy } \geq 15 \mathrm{mmol} / \mathrm{L} \text {, } \\
\text { age } \geq 35 \mathrm{y} \\
(\text { mean } 67 \mathrm{y})\end{array}$ & $\begin{array}{l}\text { high dose } \\
\text { Pyridoxine/vit } \\
\text { BI2/folic acid } \\
\text { versus low dose } \\
(\mathrm{n}=157 / / 43)\end{array}$ & $\begin{array}{l}\text { stroke, MI, death. } \\
\text { (no effect) }\end{array}$ & $2 y$ & no effect on cognition. (MMSE) \\
\hline
\end{tabular}

Abbreviations: Vit, vitamin; thcy, serum total homocysteine; FU, follow-up; y, years; TICS, telephone interview for cognitive status; MMSE, Mini-Mental State Examination; RAVLT, Rey Auditory Verbal Learning Test, WMS, Wechsler Memory Scales; CWF, category word fluency test; TMT, trail making test; CVD, cardiovascular disease; MI, myocardial infarction.

with the addition of metformin, thiazolidinediones, acarbose, or insulin if necessary to reach the target glycated hemoglobin value of $6.5 \%$ or less. After a mean of five years of follow-up, glycated hemoglobin was $6.5 \%$ in the intervention group versus $7.3 \%$ in the control group. There was a significant treatment effect on major microvascular events, mainly because of a reduction of incident nephropathy in the intervention group. There were no effects on all cause mortality or major cardiovascular events such as stroke or myocardial infarction, or on cognitive decline as measured with the MMSE or dementia, with a nonsignificant increased number of cases of incident dementia in the intervention group (61 versus 48 cases).

The ongoing Accord-Mind trial is designed to assess the effects of long term glycemic control on cognition. ${ }^{51}$ Up to now, only baseline characteristics have been published $(n=2977)$. Participants aged 55 years or older are randomized to standard care or intensive glycemic control (target $\mathrm{HbA} 1 \mathrm{c}<6.0 \%$ ) combined with either intensive treatment of dyslipidemia or systolic blood pressure (target blood pressure $<120 \mathrm{mmHg}$ ). After 40 months, the effect on cognitive outcome will be assessed using an extensive test battery including the MMSE, the Rey Auditory Verbal Learning Test (RAVLT), and the Stroop test. Evans et al found no placebo-controlled RCTs in their Cochrane review on treatment of type II DM and the development of cognitive impairment and dementia. ${ }^{52}$

\section{Multicomponent interventions}

One study with a multicomponent intervention to prevent recurrent cardiovascular events and cognitive decline in patients aged 75 years and older was identified: the DEBATE study. ${ }^{53}$ Of 400 included patients with vascular disease (mean age 80 years, all with a history of myocardial 
infarction/coronary artery disease, previous stroke or transient ischemic attack or peripheral artery disease), 199 were randomized to the intervention group in which pharmacological and nonpharmacological treatments were optimized by a geriatrician according to current guidelines. The 201 participants in the control group received care as usual (including secondary prevention programs). The mean follow-up was 3.4 years and significant reductions of blood pressure and low-density lipoprotein levels were achieved. This study was underpowered due to the occurrence of fewer events than expected. Intensified vascular care was considered feasible and safe, but no clinical benefits on cardiovascular or cognitive outcome could be identified.

\section{Discussion}

Over the past 20 years, several RCTs have focused the effect of medical treatment aimed at cardiovascular risk factors on cognitive decline and some on incident dementia. Most trials discussed in this review had large sample sizes and a considerable follow-up time. They were designed to evaluate a treatment effect on mortality and a range of vascular outcomes (including stroke, myocardial infarction, and peripheral arterial disease) and included cognitive decline or incident dementia as a secondary outcome parameter. The data on treatment of hypertension, albeit far from conclusive, are encouraging. There is a single positive trial (Syst-Eur) and a meta-analysis (Hyvet-Cog) that suggest a protective effect of hypertension treatment. Since different antihypertensive regimens were used in studies, a specific class-effect on cognition of one or more antihypertensive drugs cannot be excluded. The positive effect of oral folic acid after three years of follow-up on 3 cognitive domains in participants with high homocysteine and low vitamin B12 status which was found by Durga et al is also promising, but has not been replicated by others. For statin treatment and type II DM management, no preventive effects on cognitive decline or dementia were found. In many trials, participants were relatively young and, consequently, the incidence of dementia was low. Several forms of bias can be identified in the studies included in this review, which will be discussed below.

Selective dropout of participants due to cognitive impairment is a serious concern in the reviewed trials, especially if a study is not designed to explicitly monitor cognitive function. Cognitive impairment may lead to withdrawal of informed consent or to institutionalization. Such selective dropout could dilute a potential treatment effect and thus contribute to a type II error, especially if this form of dropout occurs more often in the control group, in case of an effective intervention. In a few trials this potential limitation has been acknowledged, leading to uncertainty about the validity of the results.

In all studies on hypertension, additional treatment with other antihypertensive medication was allowed in both the intervention group and the placebo group if necessary to achieve acceptable blood pressure values. Consequently, many patients in the control groups received antihypertensive medication, potentially decreasing the experimental contrast and thus the effect on both the cardiovascular endpoints and cognitive decline. In the cholesterol studies this additional treatment with statins other than the study drug occurred less frequently, because these studies were done before statins were widely prescribed as secondary prevention. In the homocysteine lowering trials, additional open label treatment was not a major concern.

The population under study in most trials is relatively young to find an effect on cognitive decline and certainly on incident dementia within the follow-up time. In the age-range 65-69, dementia is still relatively rare with an incidence of approximately 2.4 per 1000 , which rises sharply with age to a rate of 70.2 per 1000 at age 90 and over. ${ }^{1}$ As a consequence, the number of participants with incident dementia or significant cognitive decline was expected to be low in most studies, limiting the power of studies to find such an effect. Except for some of the homocysteine lowering trials, most trials were not powered to measure an effect on cognitive decline.

Treating cardiovascular risk factors has a clear effect on mortality, which should be considered as a competing risk for dementia. Since the incidence of dementia is strongly dependent on age, reducing mortality by preventing cardiovascular disease could lead to an actual increase of the absolute number of dementia cases in the intervention groups due to increased life expectancy. None of the included studies with a treatment effect on mortality addressed competing risks. ${ }^{54}$ Taking these considerations into account, the conclusions about cognitive decline and dementia should be interpreted with caution. Table 4 summarizes the main limitations and sources of bias which should be considered when interpreting the results of the studies discussed.

This review is limited to studies on medical treatment of five common cardiovascular risk factors. We aimed at including all randomized trials of sufficient quality assessing cognitive decline or dementia as primary or secondary outcome parameter. The association between cardiovascular risk factors and cognitive decline and dementia started to be widely recognized when the data of large observational 
Table 4 Main limitations in the reviewed studies

\begin{tabular}{|c|c|}
\hline Limitation & Remarks \\
\hline I. Age group relatively young to see any effect on dementia within follow-up & - Low number of cases: applies to most studies \\
\hline 2. High number of dropouts, potentially selective dropout due to cognitive decline & - Applies to most studies \\
\hline 3. Placebo group received additional treatment (contamination) & $\begin{array}{l}\text { - Present in most studies on antihypertensive } \\
\text { treatment and to a lesser extent in cholesterol } \\
\text { lowering trials }\end{array}$ \\
\hline 4. Bias in outcome measurement (dementia or cognitive decline) & $\begin{array}{l}\text {-All studies on hypertension and dyslipidemia assessed } \\
\text { dementia or cognitive decline as a secondary } \\
\text { outcome parameter, criteria not always clear }\end{array}$ \\
\hline 5. Competing risks not taken into account & $\begin{array}{l}\text { - Correction for increased life expectancy was not } \\
\text { applied }\end{array}$ \\
\hline 6. Sensitivity of measurement insufficient & $\begin{array}{l}\text { - Optimal screening instrument (crude or sensitive) } \\
\text { and clinical relevance are matter of debate }\end{array}$ \\
\hline 7. Short follow-up & - Optimal follow-up time is unclear \\
\hline 8. Small groups, insufficient power & - Applies to some studies on lowering homocysteine \\
\hline $\begin{array}{l}\text { 9. Patient group not selected on risk factor (no clear hypertension, } \\
\text { dyslipidemia, hyperhomocysteinemia) }\end{array}$ & $\begin{array}{l}\text { - Insufficient window of opportunity to see any effect } \\
\text { in some studies }\end{array}$ \\
\hline
\end{tabular}

studies like the Rotterdam study became available in $1997 . .^{55}$ Therefore we limited the time period of our literature search. Studies reporting on the relationship between antihypertensive drugs and cognition that were published before 1995 concentrated on the difference between two antihypertensive drugs to evaluate a negative effect on cognition on short term by a certain drug class, rather than looking for cognitive decline on the long term.

RCTs investigating lifestyle interventions including physical activity and diet were not taken into account for this review. To our knowledge, no RCTs on lifestyle interventions with a sufficiently long follow-up to assess any long-term effect on cognition or incident dementia are available.

As in any field, publication bias may have influenced the results of our search. RCTs in which no positive outcome on cognition was found might have been missed, when this secondary outcome parameter is not referred to in titles or abstracts. This is unfortunate, because when cognitive decline is adequately analyzed, a negative outcome is of equal interest to the field.

Meta-analyses of separate risk factors were not performed. For hypertension, two meta-analyses are already available and no additional studies have been published in the meantime. ${ }^{34,36}$ The trials on homocysteinemia were considered too diverse in the populations targeted and the outcomes measured to pool their results. Finally, sources of bias cannot be controlled for in a meta-analysis, while these represented an important objective in this review.

The large amount of data from observational studies on the correlation between different cardiovascular risk factors and dementia and the inconclusive results of the RCTs discussed in this review call for new RCTs with longer follow-up, in sufficiently aged populations, while avoiding methodological pitfalls specific to this field (Table 4). Perhaps different populations should be targeted (eg, participants in different age groups and with different vascular risk profiles), and perhaps other interventions should be probed (eg, combined interventions or specific drug classes). Calcium channel blockers are of special interest because they were the drug under study in the only trial in which a clear effect of blood pressure lowering on incident dementia was found. In a recently published prospective cohort study, angiotensin receptor blockers are shown to be associated with a significant reduction in the incidence of (Alzheimer's) dementia when compared to other antihypertensive drugs. ${ }^{56}$

A serious concern is that placebo-controlled trials are often not possible for obvious ethical reasons. Additionally, it is difficult to reach a sufficient level of contrast between the intervention and control group when targeting vascular risk factors in patients at high risk, since treatment of these is clearly indicated to prevent cardiovascular disease. Therefore, strategies should be designed in which for instance regular care is compared to intensive care. An interesting advantage of such trials is that they focus on the cardiovascular risk profile as a whole instead of one risk factor at a time. In the DEBATE study such an intervention showed no clinical benefit, but the groups were small $(n=199 / 201)$ and many participants were already participating in secondary prevention programs due to relatively high risk of cardiovascular disease ( $81 \%$ had coronary artery disease). At least three more RCTs on cardiovascular risk factors and cognition are ongoing. The Accord-mind study is aimed at investigating the effect of intensive diabetes control with blood pressure control or lipid lowering therapy. ${ }^{51}$ The preDIVA study investigates 
whether a nurse-led intervention aiming at improvement of the cardiovascular risk profile with an individualized approach including both lifestyle interventions and medical interventions can prevent dementia in an elderly population (70-78 years) with a 6-year follow-up. ${ }^{57}$ The Finger-study is designed to delay cognitive impairment in subjects at high risk of dementia through a multidomain individualized intervention. ${ }^{58}$

Based on the studies reviewed here we conclude that there is insufficient evidence that medical treatment aimed at cardiovascular risk factors can prevent cognitive decline or dementia. Whereas antihypertensive treatment potentially has a preventive effect, this is less clear for treatment with statins and intensified type II diabetes mellitus management. Results on therapy aimed at lowering homocysteine levels are ambiguous and more long-term follow-up trials are needed. It may well be that differential dropout, lack of power, competing risks, or other forms of selection or treatment bias have diluted possible effects. Future RCTs in other populations with different interventions and longer follow-up, specifically designed to detect an effect on cognitive decline or dementia, will hopefully address the central question whether the associations found in cohort studies can be translated to clinically relevant treatment effects on cognition.

\section{Acknowledgment}

The authors thank FS van Etten for her help with the literature review.

\section{Disclosure}

The authors report no conflicts of interest in this study.

\section{References}

1. Fratiglioni LM, Launer LJP, Andersen KM, et al. Incidence of dementia and major subtypes in Europe: a collaborative study of population-based cohorts. Neurology. 2000;54:S10-S15.

2. Viswanathan A, Rocca WA, Tzourio C. Vascular risk factors and dementia: how to move forward? Neurology. 2009;72:368-374.

3. Matthews FE, Brayne C, Lowe J, McKeith I, Wharton SB, Ince P. Epidemiological pathology of dementia: attributable-risks at death in the Medical Research Council Cognitive Function and Ageing Study. PLoS Med. 2009;6:e1000180.

4. Savva GM, Wharton SB, Ince PG, et al. Age, neuropathology, and dementia. N Engl J Med. 2009;360:2302-2309.

5. Schneider JA, Arvanitakis Z, Bang W, Bennett DA. Mixed brain pathologies account for most dementia cases in community-dwelling older persons. Neurology. 2007;69:2197-2204.

6. Snowdon DA, Greiner LH, Mortimer JA, Riley KP, Greiner PA, Markesbery WR. Brain infarction and the clinical expression of Alzheimer Disease: the Nun Study. JAMA. 1997;277:813-817.

7. Vermeer SE, Prins ND, den Heijer T, Hofman A, Koudstaal PJ, Breteler MMB. Silent brain infarcts and the risk of dementia and cognitive decline. N Engl J Med. 2003;348:1215-1222.
8. Arvanitakis Z, Wilson RS, Bienias JL, Evans DA, Bennett DA. Diabetes mellitus and risk of Alzheimer Disease and decline in cognitive function. Arch Neurol. 2004;61:661-666.

9. Gustafson D, Rothenberg E, Blennow K, Steen B, Skoog I. An 18-year follow-up of overweight and risk of Alzheimer disease. Arch Intern Med. 2003;163:1524-1528.

10. Kivipelto M, Ngandu T, Laatikainen T, Winblad B, Soininen H, Tuomilehto J. Risk score for the prediction of dementia risk in 20 years among middle aged people: a longitudinal, population-based study. Lancet Neurol. 2006;5:735-741.

11. Seshadri S, Beiser A, Selhub J, et al. Plasma homocysteine as a risk factor for dementia and Alzheimer's Disease. $N$ Engl $J$ Med. 2002;346:476-483.

12. Skoog I, Nilsson L, Persson G, et al. A 15-year longitudinal study of blood pressure and dementia. Lancet. 1996;347:1141-1145.

13. Guo Z, Fratiglioni L, Zhu L, Fastbom J, Winblad B, Viitanen M. Occurrence and progression of dementia in a community population aged 75 years and older: relationship of antihypertensive medication use. Arch Neurol. 1999;56:991-996.

14. Khachaturian AS, Zandi PP, Lyketsos CG, et al. Antihypertensive medication use and incident Alzheimer Disease: The Cache County Study. Arch Neurol. 2006;63:686-692.

15. Luchsinger JA, Tang MX, Miller J, Green R, Mayeux R. Relation of higher folate intake to lower risk of Alzheimer Disease in the elderly. Arch Neurol. 2007;64:86-92.

16. Rockwood K, Kirkland S, Hogan DB, et al. Use of lipid-lowering agents, indication bias, and the risk of dementia in community-dwelling elderly people. Arch Neurol. 2002;59:223-227.

17. Richard E, Gouw AA, Scheltens P, van Gool WA. Vascular care in patients with Alzheimer Disease with cerebrovascular lesions slows progression of white matter lesions on MRI. The Evaluation of Vascular Care in Alzheimer's Disease (EVA) Study. Stroke. 2010; STROKEAHA.

18. Fogari R, Mugellini A, Zoppi A, et al. Effect of telmisartan//hydrochlorothiazide vs lisinopril//hydrochlorothiazide combination on ambulatory blood pressure and cognitive function in elderly hypertensive patients. J Hum Hypertens. 2005;20:177-185.

19. Goldstein G, Materson BJ, Cushman WC, et al. Treatment of hypertension in the elderly: II. Cognitive and behavioral function. Results of a Department of Veterans Affairs Cooperative Study. Hypertension. 1990;15:361-369.

20. UK Prospective Diabetes Study Group. Quality of life in type 2 diabetic patients is affected by complications but not by intensive policies to improve blood glucose or blood pressure control (UKPDS 37). Diabetes Care. 1999;22:1125-1136.

21. Naor M, Steingr ${ }^{3}$ ber HJ, Westhoff K, Schottenfeld-Naor Y, Gries AF. Cognitive function in elderly non-insulin-dependent diabetic patients before and after inpatient treatment for metabolic control. $J$ Diabetes Complicat. 2001;11:40-46.

22. Ryan CM, Freed MI, Rood JA, Cobitz AR, Waterhouse BR, Strachan MW. Improving metabolic control leads to better working memory in adults with type 2 diabetes. Diabetes Care. 2006;29:345-351.

23. Testa MA, Simonson DC. Health economic benefits and quality of life during improved glycemic control in patients with type 2 diabetes mellitus: a randomized, controlled, double-blind trial. JAMA. 1998;280:1490-1496.

24. Wolters M, Hickstein M, Flintermann A, Tewes U, Hahn A. Cognitive performance in relation to vitamin status in healthy elderly German women - the effect of 6-month multivitamin supplementation. Preventive Med. 2005;41:253-259.

25. Eussen SJ, de Groot LC, Joosten LW, et al. Effect of oral vitamin B-12 with or without folic acid on cognitive function in older people with mild vitamin B-12 deficiency: a randomized, placebo-controlled trial. Am J Clin Nutr. 2006;84:361-370.

26. SHEP Cooperative Research Group. Prevention of stroke by antihypertensive drug treatment in older persons with isolated systolic hypertension: final results of the Systolic Hypertension in the Elderly Program (SHEP). JAMA. 1991;265:3255-3264. 
27. Di Bari M, Pahor M, Franse LV, et al. Dementia and disability outcomes in large hypertension trials: lessons learned from the Systolic Hypertension in the Elderly Program (SHEP) Trial. Am J Epidemiol. 2001;153:72-78.

28. Prince MJ, Bird AS, Blizard RA, Mann AH. Is the cognitive function of older patients affected by antihypertensive treatment? Results from 54 months of the Medical Research Council's treatment trial of hypertension in older adults. BMJ. 1996;312:801-805.

29. Forette F, Seux ML, Staessen JA, et al. Prevention of dementia in randomised double-blind placebo-controlled Systolic Hypertension in Europe (Syst-Eur) trial. Lancet. 1998;352:1347-1351.

30. Forette F, Seux ML, Staessen JA, et al. The prevention of dementia with antihypertensive treatment: new evidence from the Systolic Hypertension in Europe (Syst-Eur) study. Arch Intern Med 2002;162:2046-2052.

31. Tzourio C, Anderson C, Chapmen N, et al. The PROGRESS Collaborative Group. Effects of blood pressure lowering with perindopril and indapamide therapy on dementia and cognitive decline in patients with cerebrovascular disease. Arch Intern Med. 2003;163:1069-1075.

32. Lithell H, Hansson L, Skoog I, et al. The Study on Cognition and Prognosis in the Elderly (SCOPE): principal results of a randomized double-blind intervention trial. J Hypertens. 2003;21:875-886.

33. Saxby BKB, Harrington FM, Wesnes KAP, McKeith IGM, Ford GAM. Candesartan and cognitive decline in older patients with hypertension: A substudy of the SCOPE trial. Neurology. 2008;70:1858-1866.

34. Peters R, Beckett N, Forette F, et al. Incident dementia and blood pressure lowering in the Hypertension in the Very Elderly Trial cognitive function assessment (HYVET-COG): a double-blind, placebo controlled trial. Lancet Neurol. 2008;7:683-689.

35. Douma S, Petidis K, Zamboulis C, Messerli FH, Sulicka J, Gryglewska K, et al. treatment of hypertension in the elderly. $N$ Engl J Med. 2008;359:971-974.

36. McGuinness B, Todd S, Passmore AP, Bullock R. Systematic review: Blood pressure lowering in patients without prior cerebrovascular disease for prevention of cognitive impairment and dementia. J Neurol Neurosurg Psychiatry. 2008;79:4-5.

37. Heart Protection Study collaborative group. MRC/BHF Heart Protection Study of cholesterol lowering with simvastatin in 20.536 high-risk individuals: a randomised placebocontrolled trial. Lancet. 2002;360:7-22.

38. Shepherd J, Blauw GJ, Murphy MB, et al. Pravastatin in elderly individuals at risk of vascular disease (PROSPER): a randomised controlled trial. Lancet. 2002;360:1623-1630.

39. Packard CJ, Westendorp RG, Stott DJ, et al. Association between apolipoprotein E4 and cognitive decline in elderly adults. J Am Geriatr Soc. 2007;55:1777-1785.

40. McGuinness B, Craig D, Bullock R, Passmore P. Statins for the prevention of dementia. Cochrane Database Syst Rev. 2009;2:CD003160.

41. Trompet S, van Vliet P, de Craen AJM, et al. Pravastatin and cognitive function in the elderly. Results of the PROSPER study. J Neurol. 2010;257:85-90.

42. Stott DJ, MacIntosh G, Lowe GD, et al. Randomized controlled trial of homocysteine-lowering vitamin treatment in elderly patients with vascular disease. Am J Clin Nutr. 2005;82:1320-1326.

43. Kang JH, Cook N, Manson J, Buring JE, Albert CM, Grodstein F. A trial of B vitamins and cognitive function among women at high risk of cardiovascular disease. Am J Clin Nutr. 2008;88:1602-1610.
44. Viswanathan AM, Raj S, Greenberg SMM, et al. Plasma A[beta], homocysteine, and cognition: The Vitamin Intervention for Stroke Prevention (VISP) trial. Neurology. 2009;72:268-272.

45. Brady CB, Gaziano JM, Cxypoliski RA, et al. Homocysteine lowering and cognition in CKD: The Veterans Affairs Homocysteine Study. Am J Kidney Dis. 2009;54:440-449.

46. Durga J, van Boxtel MP, Schouten EG, et al. Effect of 3-year folic acid supplementation on cognitive function in older adults in the FACIT trial: a randomised, double blind, controlled trial. Lancet. 2007;369:208-216.

47. McMahon JA, Green TJ, Skeaff CM, Knight RG, Mann JI, Williams SM. A controlled trial of homocysteine lowering and cognitive performance. N Engl J Med. 2006;354:2764-2772.

48. Cukierman T, Gerstein H, Williamson J. Cognitive decline and dementia in diabetes - Çösystematic overview of prospective observational studies. Diabetologia. 2005;48:2460-2469.

49. Malouf R, Grimley EJ. Folic acid with or without vitamin B12 for the prevention and treatment of healthy elderly and demented people. Cochrane Database Syst Rev. 2008;4:CD004514.

50. The ADVANCE Collaborative Group. Intensive blood glucose control and vascular outcomes in patients with type 2 diabetes. $N$ Engl J Med. 2008;358:2560-2572.

51. Williamson JD, Miller ME, Bryan RN, et al. The Action to Control Cardiovascular Risk in Diabetes Memory in Diabetes Study (ACCORDMIND): rationale, design, and methods. Am J Cardiol. 2007;99: S112-S122.

52. Grimley Evans J, Areosa Sastre A. Effect of the treatment of type II diabetes mellitus on the development of cognitive impairment and dementia. Cochrane Database Syst Rev. 2003;1:DOI: 10.1002/14651858. CD003804.

53. Strandberg TE, Pitkala KH, Berglind S, Nieminen MS, Tilvis RS. Multifactorial intervention to prevent recurrent cardiovascular events in patients 75 years or older: The Drugs and Evidence-Based Medicine in the Elderly (DEBATE) study: a randomized, controlled trial. Am Heart J. 2006;152:585-592.

54. Beiser A, D’Agostino RB, Seshadri S, Sullivan LM, Wolf PA. Computing estimates of incidence, including lifetime risk: Alzheimer's disease in the Framingham Study. The Practical Incidence Estimators (PIE) macro. Stat Med. 2000;19:1495-1522.

55. Hofman A, Ott A, Breteler MM, et al. Atherosclerosis, apolipoprotein E, and prevalence of dementia and Alzheimer's disease in the Rotterdam Study. Lancet. 1997;349:151-154.

56. Li NC, Lee A, Whitmer RA, et al. Use of angiotensin receptor blockers and risk of dementia in a predominantly male population: prospective cohort analysis. BMJ. 2010;340:b5465.

57. Richard E, Van den Heuvel E, Moll van Charante E, et al. Prevention of Dementia by Intensive Vascular Care (PreDIVA): a cluster-randomized trial in progress. Alzheimer Dis Assoc Disord. 2009.

58. Ahtiluoto S, Rauramaa R, Soininen H, et al. Scandinavian multi-domain interventions to delay cognitive impairment. Abstract. Alzheimer's Association International Conference on Alzheimer's Disease (ICAD) Jul 2009, Vienna, Austria.
Vascular Health and Risk Management

\section{Publish your work in this journal}

Vascular Health and Risk Management is an international, peerreviewed journal of therapeutics and risk management, focusing on concise rapid reporting of clinical studies on the processes involved in the maintenance of vascular health; the monitoring, prevention and treatment of vascular disease and its sequelae; and the involvement of

\section{Dovepress}

metabolic disorders, particularly diabetes. This journal is indexed on PubMed Central and MedLine. The manuscript management system is completely online and includes a very quick and fair peer-review system, which is all easy to use. Visit http://www.dovepress.com/ testimonials.php to read real quotes from published authors. 